\title{
Müphemlik Kültürü ve İslâm: Farklı Bir İslâm Tarihi Okuması
}

Thomas Bauer, çev. Tanıl Bora

İstanbul: İletişim Yayınları, 2019, 408 sayfa

ISBN 97897505272721

Almanca olarak ilk basıldığından itibaren İslam kültür tarihine yeni bir tartışma ekleyen Thomas Bauer'in eserinin Türkçe’ye çevrilmesi ile tartışmalar Türk okuru arasında da yayılmaya başladı. On bölümden oluşan eser, İslam tarihi, kelam, tefsir, İslam hukuku, dil bilimi, psikoloji ve siyaset bilimine varıncaya kadar çeşitli alanlara ait bütüncül bir tema sunuyor. Bu alanlar arasından Kur'an-1 Kerim ilimlerine ve tefsire ayrılan pay dikkat çekiyor. Nitekim Kur'an tarihi, kıraat, tefsir, dil çalışmaları, çağdaş yorum kuramları ve Kur’an’ın tercümesi gibi meselelerden bahsetmesi konu çeşitliliğine delalet ediyor. Bütün bu çeşitlilik kitap içerisinde kendisine geniş bir yer buluyor. Bu alanlar, birbirinden kopuk bilgi yığını halinde yahut maddeleştirilmiş ders notu hüviyetinde sunulmuyor. Hepsi "müphemlik" çatısı altında, müdellel bir şekilde bir araya getirilmiş. Zaman zaman bazı konuların, bu çatının altına zorla dahil edilmesi hususu tartışmaya açı olsa da konuların müphemlik kavramı aracılığ 1 ile tek bir merkeze raptedildiği görülüyor.

Kitabın yazarı Thomas Bauer Arap dili ve edebiyatı ve İslam üzerine uzmanlaşan, halen Münster Vestfalya Wilhelm Üniversitesi’nde çalışmalarına devam eden bir araştırmacıdır. Erken dönem kültür tarihi, Arap edebiyatı, seküler şiir, din ve klasik Arapça literatür ilişkisi gibi konulara ilgili yazarın, neredeyse çeyrek asırdır üzerine düşündüğü ve yazdığı konuların süzülmüş ve odaklanmak suretiyle tek bir merkezde toplanmış hali, Müphemlik Kültürü ve İslâm'da vücut bulmuş olmalı. Bauer'in kitap içerisinde kendinden oldukça emin bir şekilde ileri sürdügü tezlerin, daha önceki müstakil çalışmalarına yaslandığı söylenebilir. Yıllar içerisinde titizlikle çalıştı̆̆ 1 konuları, akademik üsluptan kopmadan, aynı zamanda akademik metinlerin kuru atmosferine mesafeli durarak ele almış. Eseri Almanca'dan çeviren Tanıl Bora da aynı titizliği sürdürerek kitabın tercüme bir eser olduğunu okura unutturacak kadar muhteşem bir Türkçe ile kitabı dilimize kazandırmış. Kitabın adındaki "der Ambiguität"1 "muğlak" değil de çok anlamlılığı içerecek şekilde "müphem” diye çevirmesinden bile başlanabilir çeviri övgüsüne.

Kitabın içeriğine gelince, ilk yedi bölüm genel itibariyle dil-tefsir ilişkisi çerçevesinde ilerlerken son üç bölüm cinsellik, yabancılık ve kesinlik gibi 
farklı muhtevalara değiniyor. Dolayısıyla son üç konunun, kısmen bağımsızlığını ilan ettiğini söylesek de bunların ana konuyla yani müphemlikle bir şekilde bağları kurulmaya çalışılmış. Kabaca dil-tefsir ilişkisi diye tasnif ettiğimiz kısımlarda; mecaz, kinaye, müteradif, ezdad gibi dile ait olgular ve çıkış noktasını dilden alan ihtilaflar müphemlik düzleminde ele alınıyor. Bauer akademisyen alışkanlığı ile meseleye kavramsal çerçeveyi çizerek ve müphemliğin teorik zeminini anlatarak başlıyor. Kitapta pek çok defa müphemliğin tanımını yineleyen yazara göre müphemlik, "birçok söylemin yan yana olması, bunların hiçbirinin tek başına geçerlilik iddiası ileri sürmemesi, açık çelişkiler ortaya çıksa da bu çelişkileri kesinkes ortadan kaldırmaya dönük bir hırsın olmaması" anlamına geliyor. Her şeyin birden fazla anlamının oluşunu ve çift anlamlılığı, insanî varlığın özüyle ilişkilendiren Bauer'e göre müphemlik, zenginliktir. $\mathrm{O}$, müphemlikten uzak bir kesinliğe sahip olmayı, cevherini tüketmekle eşdeğer görür.

Yazarın kendi ifadelerine iltifat edecek olursak kitabın birden fazla amacı vardır. Bunlardan ilki, "Kültürel müphemliğin kültür bilimleri araştırmalarının bir nesnesi olarak yerleşmesini sağlamaktır." Diğer bir amaç ise İslam tarih yazımı ve dönemlendirmesine getirdiği eleştirinin beyanıdır. Ona göre İslam için tasavvur edilen altın çağ-duraklama-gerileme şeklindeki tasnif, yüz verilmemesi gereken bir retoriktir. Kitabın üçüncü amacının zaten kapakta alt başlıkta tecessüm ettiğini görebiliriz. Burada "Farklı bir İslam tarihi okuması" ifadesi yer alır. Oldukça alçak gönüllü ve iddiasız gibi görünen bu başlık, içerikle iştigal edildiğinde daha iyi anlaşılır. Bauer sadece okumakla, yeni bir tarih yazımı kurgulamakla yetinmemiş, İslam kültür tarihinin nasıl yazılması gerektiği hususunda yöntem geliştirmiştir. Bu noktada İslam’in hikâyesini, ötekileştirmeye kaçmadan, kendi kültürü adına ders alma, sorgulama, dolayısıyla mukayese yapma niyetiyle yazmaktadır. Zaten bunları sağlamayan tarih bilimini ilginç bulmadığını söyler. Tarih okumalarına gelince, âdeta yazarın gözlerinin önündeki tül perdede "müphemlik" işlemeleri vardır. Sanki yazar bu nakışlı perdenin ardından bütün tarihi inceler. Her meseleyi müphemlik kavramına uzak yahut yakın olması açısından değerlendirme noktasında çaba sarfeder. Tarihi ıskalayarak yani keyfî bir biçimde, istediğimiz tarihî kesitlerden bir tasavvur yaratarak sağlıklı neticelere ulaşamayacağımız kanaatine sahiptir, bu sebeple kitap boyunca hâkim vurgu, bütünsel tarih anlayışına yöneliktir.

Söz konusu müphemlik tanımından hareketle kıraat meselesini inceleyen yazar, son arzanın yani o zamana kadar nâzil olan âyet ve sûreleri Cebrâil ile Hz. Peygamber'in karşılıklı birbirine okumasının, mevcut okuma tarzlarını ilga etmediğini böylelikle sahabenin aktardığı okuma 
tarzlarında çoğulluğun sürdürülebildiğini söyler. Kıraatte çoğulluğa yaklaşımı, İbnü’l-Cezerî ve İbn Useymîn örnekleriyle izah eder. Metnin çoğulluğundan sevinç duyan ve bu çoğulluğu muhafaza etmeye, ehlîleştirmeye çalışan İbnü'l-Cezerî̀nin tavrı, müphemliğe mutabıktır. Okur sadece kıraatte değil Kur'an'ın yazıya geçirilmesi meselesinde de İbnü'l-Cezerînin aynı tutumu sürdürdüğünü yani Kur'an parçalarının ilk yazılı kaydedilişine ilgisiz davrandığını öğrenir. Öte yandan İbn Useymîn'in Kur'an’ın erken bir dönemde yazıya geçirildiğini vurgulama amacına matuf verileri tafsilatlı biçimde aktarması karşısında İbnü'l-Cezerînin tavrı, Bauer'e göre postmodern bir şahsiyeti andırır. Bauer, İbn Mücâhid ile birlikte yedi kanonik okuma tarzının sabitlenmesi meselesini okurun sorgulayacağının farkındadır. Onun nezdinde klasik ulema genellikle müphemlik karşısında hoşgörülü tasvir edilir. Öyleyse III (IX) ve IV. (X.) asırlarda yaşayan bir âlimin bu tavrı, tek tipleştirme sayılmaz mı? Bauer bu sorunu şöyle aşar: "İbn Mücâhid çoğulculuk ilkesinin hakkını vermiş ama aynı zamanda bu ilkeyi bölünme eğilimlerine mahal vermeyecek şekilde sınırlamıştır.” Fakat hâlâ yedi sınırlamasıyla alakalı bu kanaatinde tam ikna olmuş değildir ki İbnü'l-Cezerînin söz konusu sınırlamayı cehalet ve entelektüel tembellik işareti olarak lanetlediğini ekler.

Ona göre çoğaltılan Kur’an nüshalarının garnizon şehirlere gönderilmesi de müphemliği giderme eylemidir. Kur’an metninin standartlaşmasını sağlayan bu eylemde, İslam ümmetini tek dil vesilesiyle birleştirmek hedeflenmiştir. Bu vesileye müphemlik kurban edilse de ünsüzlere dayanan bu metin bir yandan da müphemliğe yeni bir alan açmıştır. Metinde harekenin ve noktalamanın olmayışı, sadece metni bilen okurun onu doğru okuyabileceği anlamına gelmekteydi. Hz. Osman'ın bile bu müphemliğe imkân tanıdığını iddia eden Bauer'e göre şayet Osman isteseydi, Kur'an metnini daha ayrıntılı biçimde kesinleştirip tek tipleştirebilirdi. Zira 22 (643) y1lına ait Yunan-Arap papirüsünde ayırıcı işaretler kullanılmıştır.

Bauer, modern dil biliminin müphemliği gemlemeye hatta imhaya yönelik tavrına mukabil müslüman müfessirlerin metindeki yorum farklılıklarını tanrının lütfu olarak değerlendirdiklerini bildirir. Tefsirde yorum farklılıklarının, insanların ilahî metinle meşguliyetini cazip kılarak onlara bilgilerini ve zekâlarını sınama imkânı veren tanrısal hile olduğunu söyler. Yorum farklılıklarına imkân sağlayan Kur’an metninin bol çeşitlemeliliği, rahmetin tezahürüdür ve kendisiyle bağ kuranlar için teşvik edici bir yöndür. XIX. yüzyılda müphemliğe müsamahasız bir kültürün karşısında "tefsirde çoğulluk"un tutunamadığını anlatır. Klasik yorumcuların bilmediği, hakiki ve tek yoruma ulaşma modası, çoğulluk fikrine galip gelmiştir. 
Bauer, Kur'an'ın tercüme edilmesi meselesindeki muhalif tutumları dahi, müphemlik kavramına iliştirmeyi becerir. Tercümeye karşı çıkanların, yobazlık ya da dogmatiklikten değil de bizatihi tercümenin anlam zenginliğini sınırlandıracağı dolayısıyla metindeki müphemliği zayıflatacağı yönündeki endişe ile hareket ettiklerini iddia eder. Çevirinin özgün metne nazaran ideolojik güdüme açık olduğunu nitekim bu doğrultuda misyonerlik gibi amaçlarla çeviriye itibar edildiğini söyler. Bu meyanda Suudi Arabistan’ın meal tecrübesine atıf yapar. Ancak İslam dünyasında Kur'an’ın tek bir çevirisinin dayatılamamış olmasını, yani dinin, politikanın gölgesinde şekillenmemesini de İslam dünyası orta sınıflarının artı hanesine yazar.

Kur'an tarihiyle alakalı Theodor Nöldeke'yi kaynak göstererek naklettiği bilgilerde yazı malzemelerinden bahseder. Bu bağlamda palmiye yaprakları, deri parçaları, koyun ya da keçi kürek kemikleri gibi malzemeleri zikrederken cam kırıklarını da bu malzemeler arasında sayması tuhaftır. Klasik literatürde camın, yazı malzemeleri arasında zikredildiğine dair bir kayıt bulunmadığı gibi camın icat edilişi de Kur'an’ın nüzul dönemine rastlamaz. Bauer'in “mübhemlik kültürü"nü “ihtimaliyet kültürü”ne transfer etmek istediği bu gibi konular izaha muhtaçtır.

Yazarın, Kur'an’ın tarihselleştirilmesi meselesini dahi müphemlik bağlamında ele alabilmesi dikkat çekicidir. Kur’an’ın tarihselleştirilmesi mevzusunda, ana çekirdeğin süzülüp günün koşullarına uyarlanması şeklindeki meşhur ikili tasniften bahseder. Fakat bu süzme işinin manipülatif ve indirgemeci olduğunu, sadece duymak istediklerimizi söylediği ve tek bir anlam üzerinde ssrar ettiği için metnin anlamını tükettiğini iddia eder, nihai tahlilde bunun müphemlikle kavgalı olduğundan dem vurur.

Kitap boyunca tek tipleştirmeye, organize olmaya, sistematikleştirmeye muhalif satırların sakladı̆̆ 1 bir ironi de vardır: Müphemliği, âdeta "dağınıklıktaki güzelliği” methetmeye dair duyulan yoğun istek, kitabın konu ve muhteva tasarımında eyleme geçmemiştir. En azından ilk yedi bölümün kendi içinde tutarlı muhteva bütünlügü bunun göstergesidir. Belki birbirinden oldukça kopuk konular olarak değerlendirebileceğimiz cinsellik, yabancılık ve kesinlik gibi konuların müstakil bir çalışma olarak yayımlanması mümkün iken kitaba dahil edilmesi, dağınıktaki güzelliği tecrübe etmeye yöneliktir.

Yazarın algısı sistematik olmayana öyle yoğunlaşmıştır ki ulûmü’l-Kur’an kitaplarının içindekiler kısmını listelerken bile konu çeşitliliğine dikkat çeker. Böylece Bauer müphemlik tezini meşrulaştırmada en basit araçlara bile yönelir. Doğrusu bunun, kitabın tezini seviyesizleştirdiği kanaatinde değilim. 
Aksine yazarın zihninin, konuyla alakalı en ayrıntı verilere karşı mıknatıs gibi işlediğini göstermesi bakımından kayda değer. Hatta tanrının mesajını tek bir dille iletmesini yani tek bir dilde vahyetmesini dahi müphemliğin terbiye edilmesi şeklinde değerlendirir.

Müphemliğin sadece teorik bilimlere değil pratik unsurlara da sindiğini iddia eden Bauer, iddiasını sanat ve mimari üzerinden örneklendirir. Cami mimarisindeki firavunî kısımların varlığını, zenginlik, şanlı geçmişten duyulan gurur ve yaban güzellerinden devşirilen esinti ile izah eder. Bunun asla malzeme yokluğuyla bir ilgisi yoktur. Bauer'in bu anlatısı, Ankara Samanpazarı'ndaki Aslanhane Camii'ni hatırlatır, burada, Roma devri malzemesi ahşap direklerin üzerinde sütun başlığı olarak kullanılmıştır. Müphemliğin maddi unsurlardaki görünümüne "üç ayrı dilden gelen ve üç farklı egemenlik telakkisini yansıtan üç ünvanın” işlendiği sikkeleri örnek veren Bauer, "Müphemlik teorisine veri sağlamak için yazar gözünün eriştiği her malzemeyi mi kullandı?” sorusunu sormaya sevkeder. Doğrusu, müphemlik kültürü onun için "nere baksam sen ordasın"a evrilmiştir.

Eserin tamamında eleştirel bir üslup göze çarpar. Yazara göre Selefîlik, oryantalizmin murat ettiği çerçeve ve hedef içerisinde teşekkül etmiş bir olgudur. İslam’ın ürettiği müphemlik alanını kısırlaştırmayı hedefleyen bu oluşumun yazar nezdinde makbul bir yanı yoktur. Bu noktada Thomas Bauer'in Batılı kültür ve tedrisat içerisinde yetişmiş bir araştırmacı olduğundan şüpheye düşebilir okur. Müphemlik kültürünü İslam’a izafe ederken bu kültürün yozlaşmasına sebep olan Batı'yı sık sık iğneler. Batı ekseriyetle, kavram üretip ayrıştırdığg ve bir şeyi denetlenebilir hale getirdiği için müphemliğe düşman olarak tasavvur edilir kitapta. Dolayısıyla kesinlik avcısı Batı, her fırsatta günah keçisi ilan edilir. Doğrusu yazarın Batı tasavvuru, linç kültüründen izler taşır. Batı’yı âdeta düşman bellediğinin aksini yapan, tepkisel koşullanmış bir varlık olarak tahayyül eder. Bu noktada biraz insafsız davranıp davranmadığı sorguya açıktır.

Kitabın Doğu ve Batı mukayesesine kilitlendiğini de hatırlatmalı. En azından Doğu'nun iki kesitine; sömürgecilik öncesi ve sömürgecilik sonrası. Bu zamansal ayırıma itibar edildiğinde, Doğu'da müphemlik önce makbulken bir anda reddedilen bir unsura dönüşüyor. Müphemlik oyun suretinde tezahür ediyor metinlerde. Doğu insanının aheste yaşamı, kapitale ve biriktirmeye fazla meraklı olmayışı sanat üzerinden de anlaşılıyor. Neticeye varmak, sonuç elde etmek değil, serüven içerisinde hayatını idame ettirmek, bu süreçte üretimde bulunmak daha keyifli geliyor Şark (Doğu) insanına. 
Bauer, eleştirilerinin kapsamının bu kadar geniş olmasına rağmen yüzeysellik tehlikesine genellikle düşmemiştir. Mesela İbn Useymîn’in müphemliği iptale yönelik tavrına, metinlerinden kanıt bulurken üslup analizleri yapar. Bu noktada, onun "el-ercah/el-esahh" değil de "es-savâb" lafzını kullandığını tespit etmesi manidardır. Çünkü Bauer’e göre, “İtiraz kabul etmez tespit kipi, klasik metinlerdeki mukayese kipini bastırmıştır."

Müphemlik Kültürü ve İslâm insan zihnini kurcalayan, emek ürünü bir metin. Bununla birlikte ufak bazı problemlerin varlığı kitabın kıymetini azaltacak türden değil. Mesela "bir müslümanın ne zaman ve kaç defa dua etmesi gerektiği”nden, “İslam'da âdet olan beş dua"dan ve "gece duası"ndan bahsedilen satırlar (s. 139-140), tercüme kaynaklı bir hata ihtimalini akla getiriyor. Muhtemelen "salat" kelimesinin "namaz" ve "dua" anlamlarına gelmesi göz ardı edilmiş. Bir başka bağlamda Bauer, Mu'tezile’yi "günahkârlar için cehennemde ebedî sürecek cezalarda ısrar edenler” olarak niteler. Yazarın Mu'tezile antipatisinin, tarihî hakikatleri çarpıtmaya sebep olup olmadığı tartışmaya açıktır. Yine kitapta "ilahiyatçılar” kelimesiyle kimin kastedildiği ilk etapta netlik kazanmazken (s. 167) ilerleyen kısımlarda (s. 206) bunun "mütekellimîn" mânasına geldiği anlaşılır. Kimi zaman ise kaynaksız konuşması (s. 217), söyleminin gücünü azaltır. Elbette esnek bir üslup benimsemesi bakımından, kaynak verme kaygısının yazarın üzerinde Demokles'in kılıcı gibi sallanmadığını (s. 163) ifade etmeli.

Yazar araştırmacılar için pek temas edilmemiş konulara işaret etmede cömert davranıyor. Mesela "Cinsel hayat tarzının oluşum koşulları araştırma nesnesi yapılmamıştır” derken konu arayanlara göz kırpıyor. Yine Yakındoğu'da Memlük ve Osmanlı dönemi Arapça edebiyatla meşgul olmanın cesaret istediği yönündeki beyanı da bu yönde teşvik kapsamına girer. Son olarak ilginç eserlere yönlendirme konusundaki cömertliğinin, sıkıcı dipnot arşivine dönüşmemesi de müspet bir vasıf olarak anılmalı.

Ayşe Uzun, Dr.Öğr. Üyesi Ankara Yıldırım Beyazıt Üniversitesi İlahiyat Fakültesi

ORCID 0000-0002-5359-6827

DOI 10.26570/isad.957317 